\title{
STABILITY OF EQUILIBRIUM IN UPRIGHT STANCE AND VOLUNTARY MOTION CONTROL IN ATHLETES-SHOOTERS IN THE PROCESS OF READY POSITION AND TARGET SHOOTING Pryimakov A.A. ${ }^{1}$, Eider E. ${ }^{1}$, Omelchuk E.V. ${ }^{2}$ \\ Szczecin University, Poland ${ }^{1}$ \\ M.P. Dragomanov National Pedagogical University ${ }^{2}$
}

\begin{abstract}
Annotation. Purpose: consists in studying the relationships between the system of equilibrium regulation in upright stance and voluntary motion control in athletes-shooters during ready position and target shooting. Material: 19 highly skilled athletes specialized in pistol shooting were studied. Physiological and biomechanical characteristics of posture and voluntary motions were assessed by methods of stabilography, electromyography and tremorometry; besides, accuracy of target shooting was registered. Results: high degree of shooting accuracy dependence on posture somatic parameters has been revealed, of which the greatest impact upon the result is exerted by low-frequency vibrations of the body general centre of mass, subjected to voluntary control. Prognostic models of shooting accuracy dependence upon the character of posture regulation during ready position and the shot have been developed. Conclusions: obtained results reveal the mechanisms of functioning and interacting of two systems of management - posture and voluntary motion. Elaborated regression models permit to model and predict posture stability and shooting accuracy during ready position and the shot.
\end{abstract}

Key words: orthograde posture, equilibrium, accuracy, relationships, athletes-shooters.

\section{Introduction}

It is known that in the process of long-term adaptation to physical loads (PL) mechanisms of upright posture regulation are improved in athletes, and provide not only the high quality and reliability of equilibrium maintenance under extreme conditions of athletic activity but determine the quality and reliability of voluntary motion control to a great extent as well $[8,14,16,19,20]$.

System approach in biological studies has demonstrated that both posture regulation and voluntary motion control are realized by hierarchically organized functional systems (FS) with clearly defined final adaptive outcome of the activity of each system [1, 2, 8, 10]. Interaction of FS may be realized at different levels of each system [8]. It depends on the structural and functional organization of both the voluntary motion and assumed posture, which preceds it and interacts with it both at the stage of "afferent synthesis" and "decision making" [1,9] and in the process of formation and realization of voluntary motion program [2, 3, 18]. However, interaction mechanisms of functional systems of upright posture regulation and voluntary motion control are rather insufficiently highlighted in the literature from system positions: that is, from position of their hierarchically organized component interactions and final adaptive results of each system [5, 10, 11]. Peculiarities of improvement of these interactions in the process of long-term adaptation to physical loads are insufficiently covered in the literature as well.

The objective of this work consists in studying the relationships between the system of equilibrium regulation in upright stance and that of voluntary motion control in athletes-shooters during ready position and target shooting.

Purpose, tasks of the work, material and methods

Methods of combined multiparameter registration of physiological and biomechanical characteristics of posture and voluntary motions including stabilography, electromyography, tremorometry, pulsometry, target shooting accuracy were used $[8,9,12]$.

Eighting highly skilled pistol shooterts participated in studies.

Mechanisms of posture regulation were studied during equilibrium maintenance in three upright stances: the Romberg stance (posture 1), the common stance (posture 2) and complicated upright stances (postures 3-4) during ready position, just before and during target shooting.

In one case the posture was complicated by four-time pistol lifting and holding in outstretched arm until fatigue (posture 3), whereas in the other - by upright stance maintenance with knee joint angle equal to $110^{\circ}$ (posture 4). In both cases testing ended in apparent signs of fatigue due to isometric activity of the upper and the lower extremity muscles.

During ready position and shot somatic and vegetative parameters of the posture and formed motion were synchronously registered along with calculation of energy expenditures. Accuracy of target shooting was recorded.

Shifts of the body general centre of mass (GCM) while maintaining equilibrium in upright stance, tremor of the hand holding the pistol and accuracy of target shooting were considered as the parameters of the "final adaptive results".

Synchronous registration of somatic, vegetative and biomechanical indices followed by respective mathematical processing allowed to examine physiological mechanisms underlying interrelated activity of two systems of control, integrating for realization of the program of accuracy motion under various conditions. Methods of variance statistics including correlation, regression, dispersion, etc. methods of statistical analysis in STATISTICA system of Windows were applied for experimental material processing [4]. 


\section{Results of the research}

The results of studies have demonstrated that pistol holding in outstretched arm in shooter's specific stance insignificantly influences equilibrium stability: high equilibrium stability was observed in athletes both during convenient and specific posture of the shooter. Amplitude of high-frequency shifts of the body GCM varied from $0,6 \pm$ 0,09 to $0,8 \pm 0.03 \mathrm{~mm}$, whereas that of low-frequency - from $0,9 \pm 0,1$ to $1,6 \pm 0,16 \mathrm{~mm}$. Some somatic characteristics of the posture, activity of muscular and cardiovascular (CV) system showed significant changes both during ready position assumption and just before the shot.

For instance, standing with pistol in outstretched arm in shooter's specific posture while aiming was accompanied with significant increase of hand tremor amplitude relative to that in initial posture, and electric activity of brachioradial muscle (BRM), tendency to increase of electric activity of deltoid muscle (DM), enhancement of CV system activity and increased energy expenditures.

Just before the shot the character of posture regulation and hand voluntary motion control during aiming appeared to change: decrease of the amplitude of slow high-amplitude shifts of the body GCM was observed in frontal and sagittal planes, whereas fast ones - in frontal plane; besides, an increase of the frequency of fast vibrations of the body GCM and decrease of slow ones in sagittal plane, tendency to reduction of heart rate (HR), tremor amplitude (TA) of hand holding the pistol and amplitude of electromyograms (EMG) of BRM and DM were noted.

Coefficients of correlation $(r)$ between somatic parameters of the posture varied during ready position from $0,44 \pm 0,03$ to $0,738 \pm 0,0002$, reflecting different interdependence of the upper extremity muscle functioning, vibrations of the body GCM and tremor of hand holding the pistol. It is noteworthy, that in this case the dependence of $\mathrm{CV}$ system functioning and energy expenditure on somatic parameters of posture stability was also manifested. to enhance.

Just before the shot interrelation between somatic parameters of the posture and their correlation with HR tended

Sustained static tension of the upper and the lower extremity muscles while holding pistol in outstretched arm in complicated stance (with knee joint angle equal to $110^{\circ}$ ) induces more expressed shifts of the parameters of posture stability, muscular and cardiac activity, accelerates fatigue development and activates mechanisms of equilibrium correction in orthograde posture. The above is accompanied with synchronization of arm and the lower extremity vibrations, appearance of spike discharges of motoneurons on EMG and increase of energy expenditures, which finds its manifestation in high degree of correlations between parameters.

Improvement of the mechanisms of posture stability regulation and voluntary motion control in top level shooters is characterized by short-term decrease of EMG amplitude of deltoid and brachioradial muscles, tremor amplitude of hand holding the pistol and the main vibrations of the body GCM just before the shot.

Insignificant decrease of HR may be observed in some shooters in specific posture at the moment preceding the shot. Despite the fact that direct voluntary control for discrete involuntary vibrations of the body GCM is not possible (as according to N.A.Bernstein (2) their regulation is realized with participation of rubrospinal level of motion control), mechanisms of tremor amplitude, the body GCM vibrations and HR decrease are indirectly activated by top level athletes.

An artificial introduction of confounding factors (change of habitual posture, additional vestibular irritants, prolonged isometric regime of muscular activity) impairs the quality of posture regulation and is accompanied with increased energy expenditures and deterioration of shooting accuracy (Table 1).

Table 1

Somatovegetative indices and accuracy of shooting under different conditions of upright posture maintenance

\begin{tabular}{|c|c|c|c|c|}
\hline \multirow[t]{2}{*}{ Indices } & $\begin{array}{l}\text { Initial posture of } \\
\text { shooter }\end{array}$ & $\begin{array}{l}\text { Pistol holding until } \\
\text { fatigue }\end{array}$ & \multicolumn{2}{|c|}{$\begin{array}{l}\text { Low stance maintenance } \\
\text { until fatigue }\end{array}$} \\
\hline & $\begin{array}{ll}\mathrm{X} & \pm \mathrm{M}\end{array}$ & $\pm \mathrm{M}$ & $\mathrm{X}$ & $\pm_{\mathrm{M}}$ \\
\hline Tremor amplitude, $\mathrm{mm}$ & 7,5 & 0,27 & 10,9 & 1,6 \\
\hline $\begin{array}{c}\text { Sagittal stabilogram ampl., } \\
\text { mm }\end{array}$ & 0,1 & $1,78 \quad 0,14$ & 4,76 & 0,57 \\
\hline EMG of DM, mkV & $321 \quad 20,0$ & $382,9 \quad 25,0$ & 513,0 & 53,3 \\
\hline EMG of BRM, mkV & $232 \quad 17,6$ & $219,6 \quad 19,9$ & 295,3 & 17,9 \\
\hline EMG of QMT, mkV* & $74.6 \quad 1,4$ & $16,7 \quad 3,0$ & 221,1 & 9,2 \\
\hline EMG of GM, mkV & $74.6 \quad 3,4$ & $107,4 \quad 8,4$ & 184,2 & 14,4 \\
\hline HR, bt·min -1 & $92.8 \quad 1,7$ & $102,4 \quad 2,5$ & 111,2 & 3,2 \\
\hline
\end{tabular}




\begin{tabular}{|c|c|c|c|c|}
\hline \multirow[t]{2}{*}{ Indices } & $\begin{array}{l}\text { Initial posture of } \\
\text { shooter }\end{array}$ & $\begin{array}{l}\text { Pistol holding until } \\
\text { fatigue }\end{array}$ & \multicolumn{2}{|c|}{$\begin{array}{l}\text { Low stance maintenance } \\
\text { until fatigue }\end{array}$} \\
\hline & $\pm_{\mathrm{M}}$ & $\pm_{\mathrm{M}}$ & $\mathrm{X}$ & $\pm_{\mathrm{M}}$ \\
\hline Energy expenditure, kcal & $\begin{array}{ll}4.2 & 0,2\end{array}$ & 4,45 & 5,15 & 0,12 \\
\hline Shooting result (5 shots) & $49.4 \quad 0,29$ & $48,45 \quad 0,53$ & 46,74 & 0,91 \\
\hline
\end{tabular}

*EMG of QMT = electromyogram of quadriceps muscle of thigh; EMG of GM = electromyogram of gastrocnemius muscle.

Despite the fact that confounding factors (prolonged pistol holding in outstretched arm and low stance until fatigue) decrease posture stability, increase and synchronize various vibrations of standing person, more fit athletes damp down these vibrations before the shot, preventing their "spreading" on the arm holding the pistol. Unfit athletes do not possess this capacity, therefore the shot is made in the face of decreased equilibrium stability, increased TA of arm, EMG of DM and BRM, HR and energy expenditures, which leads to impaired shooting accuracy.

Correlation analysis has demonstrated that under complicated standing conditions (while holding pistol in outstretched arm until fatigue or keeping knee joint angle equal to $110^{\circ}$ ), interaction of functional systems of posture stability control and accuracy of voluntary motion tends to increase.

Analysis of interactions at the moment of ready position and just before the shot shows that control for posture stability, tremor vibrations of arm holding the pistol and HR at the moment preceding the shot, is dependent on the character of posture regulation during ready position (15-10 sec before the shot). This is evidenced by revealed high positive correlations, reflecting dependence of amplitude of the body GCM shifts, arm tremor, and EMG at the moment preceding the shot on respective indices registered during assuming ready position (Table 2).

Table 2

Interactions of somatic indices and HR of athletes-shooters, recorded just before the shot with analogous indices registered while assuming ready position

\begin{tabular}{|c|c|c|c|c|c|c|c|c|c|}
\hline \multirow{3}{*}{ 总 } & \multirow{3}{*}{\multicolumn{2}{|c|}{ Indices: }} & \multicolumn{7}{|c|}{ Before the shot: } \\
\hline & & & \multirow{3}{*}{$\begin{array}{c}\text { tremor } \\
\text { amplitude } \\
-0,725\end{array}$} & \multicolumn{3}{|c|}{ stabilogram } & \multicolumn{2}{|c|}{ EMG } & \multirow[t]{2}{*}{ HR } \\
\hline & & & & sag. $A_{1} *$ & fr. $F_{2}$ & fr. $A_{2}$ & $\mathrm{DM}$ & BRM & \\
\hline \multirow[t]{2}{*}{$\mathrm{R}$} & \multirow[t]{2}{*}{ tremor } & frequency & & & - & & - & - & $-0,770$ \\
\hline & & amplitude & 0,966 & & - & & - & - & 0,921 \\
\hline \multirow{4}{*}{$\begin{array}{l}\mathrm{a} \\
\mathrm{d} \\
\mathrm{y}\end{array}$} & \multirow{4}{*}{$\begin{array}{c}\text { stabilogra } \\
\mathrm{m}\end{array}$} & sag. $A_{1}$ & - & 0,605 & - & $-0,617$ & - & - & 0,654 \\
\hline & & sag. $A_{2}$ & - & 0,685 & - & 0,630 & - & - & - \\
\hline & & sag. $F_{1}$ & - & 0,751 & - & - & - & - & - \\
\hline & & fr. $F_{2}$ & - & - & $-0,778$ & - & & & - \\
\hline \multirow[b]{2}{*}{$\mathrm{o}$} & \multirow[t]{2}{*}{ EMG } & $\mathrm{DM}$ & - & - & & - & 0,878 & 0,898 & \\
\hline & & BRM & & - & & - & 0,898 & 0,918 & 0,748 \\
\hline S. & \multicolumn{2}{|l|}{ HR } & & & & - & & 0,748 & 0,789 \\
\hline
\end{tabular}

* Notes: sag. - sagittal, fr. - frontal, $\mathbf{A}_{1}$ - amplitude of high-frequency vibrations, $\mathbf{A}_{2}$ - amplitude of lowfrequency vibrations, $\mathbf{F}_{\mathbf{1}}$ - frequency of low-amplitude vibrations, $\mathbf{F}_{\mathbf{2}}$ - frequency of high-amplitude vibrations.

Correlation analysis results indicate that the greater are the arm TA while assuming ready position, the body GCM vibrations, muscle electric activity and HR (10-15 sec before the shot), the higher are their meanings just before the shot and vice versa. Fit athletes tend to manifest more expressed capacity for reduction of these vibration amplitude and HR decrease before the shot.

The less is the posture stability at the beginning of ready position, the more expressed are correctional reorganizations of posture just before the shot in athletes: high correlation interactions have been observed between amplitude of the body GCM and tremor while assuming ready position and the degree of their decrease just before the shot $(r=0,913<0,01$ and $r=0,717<0,01$, respectively), which is indicative of control on the basis of signals of negative feedback (2). 
At the same time, deterioration of equilibrium stability in sagittal plane while assuming ready position activates compensatory responses aimed at decrease of amplitude $(\mathrm{r}=-0,677 \pm 0,008)$ and increase of frequency $(\mathrm{r}=0,736 \pm 0,003)$ of tremor, rise in frequency of the main vibrations of frontal stabilogram $(r=0,623 \pm 0,02)$ just before the shot. Increase of amplitude of the main vibrations of the body GCM in frontal plane while assuming ready position leads to decrease of amplitude of deltoid muscle EMG $(\mathrm{r}=-0,669 \pm 0,009)$ just before the shot.

Analysis of regulation mechanisms of posture stability during ready position shows that programing of responses, which provide maximal accuracy of shooting in case of regular hindrances to posture maintenance, includes the development of efficient program anticipating posture reorganization, consisting in activation of motor units, stabilization of equilibrium and joint angle during ready position assumption and just before the shot, between the parameters of which and voluntary motion accuracy there exist high correlations.

The findings demonstrate that arm tremor depending on EMG activity of DM during ready position exerts the greatest influence on accuracy of shooting: there exist strong negative linear dependences between arm TA, electric activity of DM and shooting accuracy - the higher are arm TA and electric activity of DM, the lower is the result of shooting.

Presented in Fig.1 coefficients of correlation and determination, regression models reflect high dependence of the result of accuracy motion on posture somatic parameters recorded during ready position and just before the shot under ordinary and complicated conditions of standing: the higher is the amplitude of tremor, body GCM vibrations and electric activity of DM and BRM, the lower is the result of shooting, and vice versa.

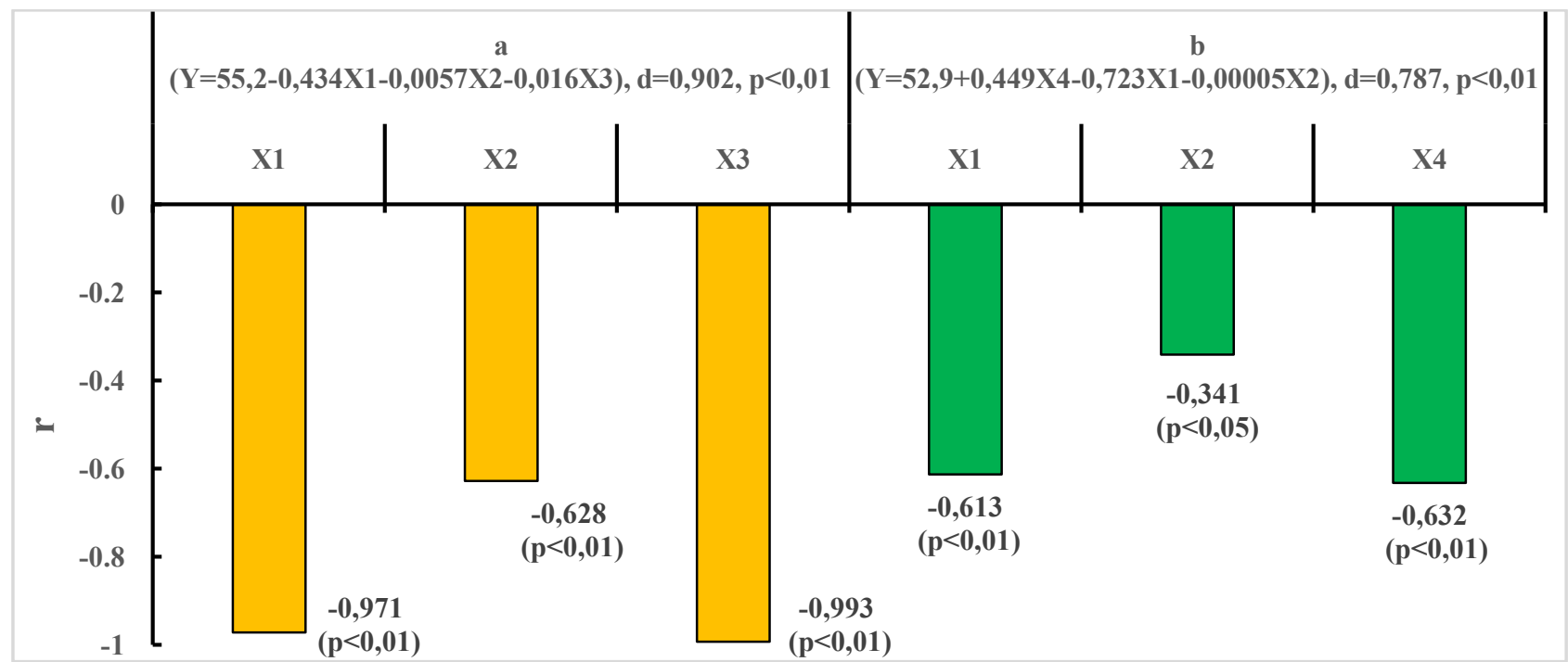

Fig.1. Coefficients of correlations and regression models reflecting association between accuracy of target shooting and posture somatic parameters, recorded during ready position (a) and just before the shot (b): $r-c o e f f i c i e n t s$ of correlation; $Y$ - result of shooting, points; X1 - tremor amplitude, $m m ; X 2-E M G$ of DM, mkV; X3 - EMG of BRM, $m k V ; X 4$ - amplitude of sagittal stabilogram, mm.

Coefficients of pair and multiple correlations, determination and regression equations indicate that accuracy of voluntary motion is determined not only by partial contribution of individual parameters of examined system but their interaction as well, as a result of which there occurs dependence, different in the degree and the form from pair correlations, which is approximated rather precisely by means of multiple regression equations presented in the Figure.

\section{Discussion.}

Carried out studies have confirmed the findings of several authors indicating close association between the parameters of shooter's upright posture stability and accuracy of target shooting $[6,7,14-16]$. Dependence of shooting accuracy on the peculiarities of cardiac activity has been also revealed, which corresponds to the results reported by several authors $[6,13]$.

At the same time, conducted studies have specificated the mechanisms of posture regulation while assuming ready position and just before the shot as well as their associations providing optimum background conditions for realization of voluntary accurate motion - target shooting.

For instance, it has been revealed that at the beginning of aiming the character of deviating posture regulation is manifested providing alteration of equilibrium stability control during the shot, depending on stability in ready position.

Statistical processing of findings has revealed rather strong influence of individual somatic characteristics of posture and their interactions upon the mechanisms of accurate volitional motion control during ready position and target shooting. This is also indicative of close interrelation of regulation mechanisms of two systems of control: the system of upright posture stabilization and that of voluntary motion. 
Analysis of coefficients of correlation, determination and regression equations, presented in Fig.1, demonstrates high degree of dependence of shooting accuracy on simultaneous interrelated impact of posture somatic parameters, of which the greatest influence on the result is exerted by relatively slow, low-frequency vibrations of the body GCM, sequacious to voluntary control. Top level athletes have a knack for damping them down, manifesting higher quality of posture stability control at the moment of accurate motion realization.

On the basis of obtained results it is safe to conclude that formed program of realization of forthcoming accurate motion includes both standard parameters of posture and voluntary motion and the mechanisms of correcting their interaction when confounding factors and hindrances are acting, thus providing control of perturbation and deviation.

As a result of the above, high accuracy during the shot is achieved in adapted athletes at well-timed (in accordance with created standard and the character of correctional inverse afference) preliminary posture reorganization - its stability and biomechanical parameters.

During fatigue in less adapted to physical load athletes, one may observe increase of amplitude and synchronism of vibrations of different body links in upright posture, loss of ability to damp down these vibrations, which are propagating to the barrel, thus deteriorating shooting quality the more, the higher are their amplitude and the degree of synchronization.

The worse posture stability at the beginning of ready position, the more expressed are its correctional reorganizations just before the shot: the more decreased are the arm TA, the body GCM vibrations; besides the tendency to HR reduction is observed. The above reflects deviation control on the basis of negative feedback.

Hence important tasks follow: a) elaboration of means and methods of posture stabilization during ready position, aimed at improvement of stability within equilibrium zone, decrease of amplitude of tremor, muscle electric activity, HR just before the shot; b) usage of prognostic models allowing to predict the system state, the character of posture control just before the shot and accuracy of voluntary motion realization on the basis of initial data.

\section{Conclusions.}

1.Obtained results reveal the mechanisms of functioning and interacting of two control systems - posture and voluntary motion.

2.High degree of shooting accuracy dependence on simultaneous interacting impact of posture somatic parameters has been revealed, of which the greatest influence on the result is exerted by relatively slow, low-frequency vibrations of the body GCM, sequacious to voluntary control.

3. Elaborated regression models permit to model and predict: 1) posture stability, the character of its regulation just before the shot depending on analogous parameters during ready position; 2) change of CV system activity at the moment of shot depending on posture stability, activity of muscles, tremor of arm holding the pistol during ready position and just before the shot; 3 ) accuracy of shooting depending on the character of posture regulation during ready position and the shot.

\section{References:}

1. Anokhin P.K. Ocherki po fiziologii funkcional'nykh sistem [Essays on the physiology of functional systems], Moscow, Medicine, 1975, 448 p. (in Russian)

2. Bernshtejn N. A. O postroenii dvizhenij [On the construction of movements], Moscow, Medicine, 1947, 255 p. (in Russian)

3. Bernshtejn N.A. O lovkosti $i$ ee razvitii [About dexterity and its development], Moscow, Physical Culture and Sport, 1991, 288 p. (in Russian)

4. Borovikov V.P., Ivchenko G.I. Prognozirovanie $v$ sisteme STATISTICA $v$ srede Windows [Forecasting in the STATISTICA for Windows], Moscow, Finance and Statistics, 2006, 275 p. (in Russian)

5. Bozerzhan Zh. Spravochnik po sportivnoj strel'be [Handbook of sports shooting], Rostov on Don, Phoenix, 2006, 192 p. (in Russian)

6. Ivanov K.O., Kubriak O.V. Vliianie oshchushchenij ot serdca i stabil'nosti pozy na tochnost' strel'by v predstavlenii elitnykh strelkov [Influence of feelings from the heart and stability pose on accuracy in the representation of elite shooters]. Vestnik sportivnoj nauki, 2011, no.5, pp. 13-22. (in Russian)

7. Kudelin A. Kak povysit' ustojchivost'? [How to improve stability?]. Oruzhie. 2005, no.2, pp. 64-66. (in Russian)

8. Prijmakov O.O. Vzaiemozv'iazok mekhanizmiv reguliuvannia stijkisti postavi ta svavil'nogo tochnist'n'ogo rukhu u sportsmeniv [Relationship resistance mechanisms regulating posture and arbitrary precision motion in athletes]. Fiziologichnij zhurnal. 1995, vol.41, no.3-4, pp. 23-28. (in Ukrainian)

9. Prijmakov A.A. Vzaimosviazi sistem regulirovaniia ravnovesiia v vertikal'noj stojke i upravleniia proizvol'nymi dvizheniiami u sportsmenov-strelkov [Relationship management systems of equilibrium in the vertical rack and control voluntary movements in athletes-riflemen]. Fizicheskoe vospitanie studentov. 2010, no.3, pp. 75-77. (in Russian)

10. Sudakov K.V. Funkcional'nye sistemy organizma [Body functional systems], Moscow, Medicine, 1987 , 432 p. (in Russian)

11. Tarasova L.V. Faktory ustojchivosti sistemy «strelok-oruzhie» v trenirovke vysokokvalificirovannykh strelkov [Resistance factors of the "shooter-weapon" in the training of highly skilled riflemen]. Vestnik sportivnoj nauki, 2009, no.3, pp. 25-27. (in Russian) 
12. Boloban V. Systemic stabilography: methodology of measuring, estimating and controling sportsman body balance and the system of bodies. Coordination motor abilities in scientific research. Biala Podlaska, 2005, pp. 102-109.

13. Christodonlou V.X., Dinas P.C., Baliamis N.G., Felouris A.D. Changes in heart rate variability during an archery competition. 15th annual congress of the European College of Sport Science: book of abstracts. 2010, no.15, pp. 339.

14. Era P., Konttinen N., Mehto P., Saarela P., Lyytinen H. Postural stability and skilled performance - a study on toplevel and naive rifle shooters. Journal of Biomechanics, 1996, vol.29, no.3, pp. 301-306.

15. Herpin G., Gauchard G.C., Lion A., Collet P., Keller D., Perrin P.P. Sensorimotor specificities in balance control of expert fencers and pistol shooters. Journal of Electromyography and Kinesiology. 2010, vol.20, no.1, pp. 162169.

16. Lakie M. The influence of muscle tremor on shooting performance. Exp. Physiol. 2010, vol.95, no.3, pp. 441-450.

17. Matthias E., Schandry R., Duschek S., Pollatos O. On relationship between interoceptive signal information and the process of visual stimulus processing. Int. J. Psychophysiol. 2009, vol.72, no.2, pp. 154-159.

18. Perrot C., Deviterne D., Perrin P. Influence of training on postural and motor control in a combative sport. $J$. Hum. Mov. Studies. 1998, no.35, pp. 119-135.

19. Terekhov A.V. Concerning the nature of slow component in postural sway. European Workshop on Movement Science. 2005, Vienna, 2005, 123 p.

20. Terekhov A.V., Levik Yu.S. The forming of the reference vertical in the orthograde posture stabilization task. Progress in motor control. 2006, no.5, pp. 4-20. 
Pryimakov 0.0.: http://orcid.org/0000-0003-0351-486X; aprim@bk.ru; Szczecin University; al. Piast 40B, Block 6, 71-065 Szczecin, Poland.

Eider Ezhy: http://orcid.org/0000-0002-8401-6442; sekretariat.wkfipz@ univ.szczecin.pl; Szczecin University; al. Piast 40B, Block 6, 71-065 Szczecin, Poland.

Omelchuk O.V.: http://orcid.org/0000-0001-6184-1362; omelchuk58@ mail.ru; M.P. Dragomanov National Pedagogical University; ul. Turgenevskaia 3-9, Kiev, 01000, Ukraine.

Cite this article as: Pryimakov A A, Fider E. Omelchuk EV. Stability of equilibrium in upright stance and voluntary motion control in athletes-shooters in the process of ready position and target shooting. Physical education of students, 2015, no.1, pp. 36-42. http://dx.doi.org/10.15561/20755279.2015.0106

The electronic version of this article is the complete one and can be found online at: http://www.sportpedu.org.ua/html/arhive-e.html

This is an Open Access article distributed under the terms of the Creative Commons Attribution License, which permits unrestricted use, distribution, and reproduction in any medium, provided the original work is properly cited (http:// creativecommons.org/licenses/by/3.0/deed.en).

Received: 12.11.2014

Accepted: 12.12.2014; Published: 30.12.2014 